\title{
Development of a Dietary Habit Self-Management Skills Scale for Post-Gastrectomy Cancer Patients in Japan
}

\author{
Miharu Ogasa ${ }^{1,2}$ \\ ${ }^{1}$ Faculty of Nursing, Doshisha Women's College of Liberal Arts, Kyoto, Japan \\ ${ }^{2}$ Doctoral Program, Graduate School of Nursing, Osaka Medical College, Osaka, Japan \\ Email:mogasa@dwc.doshisha.ac.jp
}

How to cite this paper: Ogasa, M. (2017) Development of a Dietary Habit Self-Management Skills Scale for Post-Gastrectomy Cancer Patients in Japan. Health, 9, 17501775.

https://doi.org/10.4236/health.2017.913128

Received: November 13, 2017

Accepted: December 8, 2017

Published: December 11, 2017

Copyright $\odot 2017$ by author and Scientific Research Publishing Inc. This work is licensed under the Creative Commons Attribution International License (CC BY 4.0).

http://creativecommons.org/licenses/by/4.0/ Open Access

\begin{abstract}
Purpose: The purpose of the present study was to develop a Dietary Habit Self-Management Skill (DHSMS) scale, and to test the reliability and validity of this scale. Methods: A questionnaire survey was then conducted using a 69-item DHSMS scale (second draft) for which content validity had been confirmed. The participants were post-gastrectomy cancer patients aged from 40 to under 80 years who had undergone initial gastrectomy with an interval of from 1 month since discharge to $<3$ years post-operative. Results: The scale is a second-order factor model with "Dietary habit self-management skills" as a higher-order factor, four factors-"Skill to form partnerships with other important people", "Skill to prevent or cope with post-gastrectomy disorder", "Skill to grasp issues accompanying post-gastrectomy disorder", and "Self-efficacy"-and 27 items. The construct validity of the scale was confirmed. Cronbach's alpha coefficient of the DHSMS scale was 0.915. The criterionrelated validity of the DHSMS scale was confirmed based on the correlations between overall DHSMS scale scores and "Number of post-gastrectomy disorder symptoms experienced", the score for the subscale "Skill to grasp issues accompanying post-gastrectomy disorder" and "Number of post-gastrectomy disorder symptoms experienced", and the subscale "Self-efficacy" and the SF-8. Discussion: By using patients' self-administered DHSMS scale scores, medical professionals are able to assess the level of a patient's self-management skills and the status of their dietary habits as a result of post-gastrectomy disorder.
\end{abstract}

\section{Keywords}

Self-Management Skill, Gastric Cancer, Dietary Habit, Scale Development 


\section{Introduction}

The death rate from gastric cancer is falling in Japan due to the spread of cancer testing and advances in diagnostic and treatment techniques, which have enabled early detection and treatment. Nonetheless, the actual number of cases is rising every year [1].

The main curative treatment for gastric cancer is surgery. If all or part of the stomach is surgically removed, the anatomical structure and physiological function of the stomach change, and many patients who undergo removal of the stomach experience postoperative disorders. Post-gastrectomy disorder is caused by multiple factors, including changes in retention function, nutrition absorption function, digestive hormone secretion, and intestinal flora, and for this reason, there is a low probability of improvement over time [2] [3]. Consequently, prevention of and coping with the physical symptoms of post-gastrectomy disorder is an unavoidable issue for post-gastrectomy cancer patients, who have to self-manage their own dietary habits in accordance with changes in bodily function.

However, hospital stays in Japan are becoming increasingly shorter owing to health care reform and the growth of minimally invasive surgical procedures [4]; therefore, it is difficult for post-gastrectomy cancer patients to establish dietary habit self-management with only the support of nurses during the hospital stay. Patients who have not established adequate self-management suffer dietary stress and disruption to daily and social life as a result of the appearance of physical symptoms of post-gastrectomy disorder [5] [6], which reduces their quality of life (QOL) [7] [8]. For this reason, post-gastrectomy cancer patients working on their own dietary habit self-management and continuing it independently has become an important issue. It is therefore essential that medical professionals give support tailored to the particular circumstances of patients and encourage them to acquire the self-management skills that suit them individually.

Studies to date in Japan into the dietary habits of post-gastrectomy patients have often used physical indices that measure food intake, nutritional status, and symptoms of discomfort after eating to evaluate patients' dietary behavior [9]. Nakamura et al. [3] devised the Dysfunction after Upper Gastrointestinal Surgery (DAUGS) system to evaluate the degree of functional impairment caused by upper gastrointestinal cancer surgery objectively. In addition, the Japan PostGastrectomy Syndrome Working Party [10] developed the Post-Gastrectomy Syndrome Assessment Scale (PGSAS) as a tool to assess post-gastrectomy QOL. However, these evaluation indices measure the physical symptoms of post-gastrectomy cancer patients and QOL specifically related to these symptoms; they cannot readily be used to assess patients' self-management skills. Even in countries where gastrectomy is used not only for gastric cancer, but also for obesity, postoperative progress and educational interventions in post-gastrectomy patients are assessed by physical indices such as nutritional status and body weight, 
QOL, and knowledge of disease [11] [12] [13], and no assessment scales have been developed for dietary habit self-management skills in post-gastrectomy patients.

The development of a scale for the assessment of the dietary habit self-management skills in post-gastrectomy cancer patients is therefore essential to provide support that facilitates dietary habit self-management.

\section{Purpose of the Study}

The purpose of the present study was to develop a Dietary Habit Self-Management Skills (DHSMS) scale for providing support to post-gastrectomy cancer patients in promoting their own self-management, and to test the reliability and validity of this scale.

\section{Definition of Terms}

\subsection{Dietary Habits}

In the present study, dietary habits are defined as "the series of eating behaviors and the eating environment related to preventing or coping with post-gastrectomy disorder in the everyday life of post-gastrectomy cancer patients."

\subsection{Self-Management Skills}

In the present study, self-management skills are defined on the basis of the results of Lorig \& Holman [14] as "the problem-solving, decision-making, resource utilization, formation of a patient-provider partnership, taking action, and action that are required by post-gastrectomy cancer patients to cope with the tasks of medical management, role management, and emotional management, and the acquisition of these through experience."

\section{Drawing up the Dietary Habit Self-Management Skills Scale Items}

\subsection{Clarification of the Construct for Measurement}

Based on the results of Lorig and Holman [15], the basic premise of the present study is that there are three tasks in the dietary habit self-management of post-gastrectomy cancer patients: medical management to prevent and cope with the physical symptoms of post-gastrectomy disorder through dietary habits, role management to regulate social roles with regard to post-gastrectomy dietary habits, and emotional management to regulate negative emotions with regard to post-gastrectomy dietary habits. The core dietary habit self-management skills of post-gastrectomy cancer patients are the problem-solving, decision-making, resource utilization, formation of a patient-provider partnership, taking action, and action that are required to respond to these three tasks. Lorig and Holman [14] based their problem-solving on the model of D'Zurilla, and in the present study, problem-solving is taken to comprise the six elements of problem recognition, problem analysis and judgment, establishment of goals for problem-solv- 
ing, planning solution strategies, implementing solution strategies, and evaluation of results. In addition, Lorig and Holman [14] consider taking action to be based on the problem-solving and self-efficacy models, and in the present study, taking action is viewed from the perspective of self-efficacy. The skill of decision-making is a prerequisite for problem-solving, resource utilization, formation of a patient-provider partnership, and taking action; therefore, decisionmaking cannot be handled as an independent element.

In light of the above, the dietary habit self-management skills of post-gastrectomy cancer patients were taken to include the elements of problem-solving (problem recognition, problem analysis and judgment, establishment of goals for problem-solving, planning solution strategies, implementing solution strategies, and evaluation of results), resource utilization, formation of a patientprovider partnership, and self-efficacy, which are the skills needed to address the three tasks of medical, role, and emotional management with regard to dietary habits.

It was therefore decided that the DHSMS scale would measure the details and the degree of problem-solving skills, resource utilization skills, formation of a patient-provider partnership skills, and self-efficacy, which are the skills necessary for addressing the three tasks of medical, role, and emotional management with regard to dietary habits in post-gastrectomy cancer patients.

\subsection{Formation of Question Items}

For the present study, to cover the dietary habit self-management skills of post-gastrectomy cancer patients exhaustively, items were extracted from the perspective of medical science, nursing science, and patients from research papers that clarify the dietary habits and self-management of post-gastrectomy cancer patients, publications that deal with the dietary habit self-management of post-gastrectomy cancer patients, the medical care handbook published by the Japan Post-Gastrectomy Syndrome Working Party and the Japanese Society for Gastro-Surgical Pathophysiology [15], and publications by patient groups containing coping methods for patients with post-gastrectomy disorder. Text and words recording the elements of the dietary habit self-management skills of post-gastrectomy cancer patients were extracted from a total of 34 target references. The selected text and words were classified using a matrix with the three tasks of medical, role, and emotional management along the vertical axis, and the elements of problem-solving (problem recognition, problem analysis and judgment, establishment of goals for problem-solving, planning solution strategies, implementing solution strategies, and evaluation of results), resource utilization, formation of a patient-provider partnership, and self-efficacy along the horizontal axis. The validity of each field of the matrix as a question item was closely examined in collaboration with specialists in nursing science, and similar items were integrated. A total of 118 codes that were eventually collected were taken as potential question items. 


\subsection{Codification of Question Items and Scale Formation}

The content of the question items needed to be expressed in such a way that they could be understood equally by all post-gastrectomy cancer patients, regardless of knowledge or experience. To ensure that the question items were clear and concise, the phraseology used for the question items was codified with care so that there were no double negatives and that single items did not contain multiple, differing details.

The Likert method, in which responding is easy and scoring is straightforward, was adopted for the DHSMS scale, as it is to be used on patients that include elderly people. The Likert method typically uses a scale ranging from 3 to 7 points. Having fewer steps from which to choose can reduce the burden on the respondent, but less information is obtained [16]. In addition, Japanese people tend to respond with the neutral category [16]. Use of a neutral category was therefore avoided, and the selection set comprised the following six items regarding the level of agreement with the question item: strongly disagree ( 0 points), disagree (1 point), somewhat disagree ( 2 points), somewhat agree ( 3 points), agree (4 points), and strongly agree (5 points).

\subsection{Examination of Content Validity}

The content validity of the question items was examined by seven nursing science specialists involved in oncology nursing education and practice, and one nutritionist involved in dietary interventions with post-gastrectomy cancer patients. The question items that had been drawn up were investigated in accordance with the following criteria: 1) Are the details of the dietary habit selfmanagement skills of post-gastrectomy cancer patients definitely reflected?; 2) Does the number of items fully cover the dietary habit self-management skills of post-gastrectomy cancer patients?; 3) Is the scale valid for use in clinical settings?; 4) Is the phraseology easy for patients to respond to?; and 5) Are there any items that are difficult for patients to respond to? Question items were then examined together with the nursing science specialists to determine whether they concurred with the definition of dietary habit self-management skills in post-gastrectomy cancer patients. Next, items were selected and the phraseology was revised until all members were in agreement. The resulting scale, comprising 69 items for which content validity had been confirmed, was taken as the DHSMS scale (first draft).

\subsection{The Pretest and Revision of the Dietary Habit Self-Management Skills Scale (First Draft)}

To examine the face validity of the DHSMS scale (first draft) and refine the question items, a pretest was carried out on post-gastrectomy cancer patients. The items for evaluation in the pretest were: 1) Were the patients able to understand the question items?; 2) Were there any question items toward which patients felt resistance or discomfort?; 3) Were there any question items to which 
patients were unable to respond?; 4) Was the scale fit for the purpose?; 5) Was the time needed for responses suitable?; and 6) Is it possible to obtain fluctuating data?

\subsubsection{Participants}

The study targeted patients aged from 40 to under 80 years who had undergone gastrectomy for stomach cancer at a designated cancer hospital and were from one month following discharge to $<3$ years postoperative. There were a total of 10 participants (nine men, one woman). The mean age was 70.4 years (range, 59 - 79 years), and the mean postoperative period was 16.6 months ( 1 month - 2 years 9 months).

\subsubsection{Data Collection Method}

A self-administration survey was carried out using the DHSMS scale (first draft), and the responses were timed. After completion of the responses, an interview lasting about $15 \mathrm{~min}$ was carried out. In the interview, respondents were asked whether any items were difficult to understand, gave feelings of discomfort, or difficult to answer, and if so, the reasons why.

\subsubsection{Data Analysis Method}

In the analysis, the data for each item of the DHSMS scale (first draft) were checked for a ceiling effect or a floor effect to see if there was any distortion. The statistical software used was SPSS Statistics 23 (IBM Corp., Armonk, NY).

\subsubsection{Results of the Pretest and Selection of the Question Items}

The results of the pretest showed that the mean time required for responding to the DHSMS scale (first draft) was $12.4 \mathrm{~min}$ (shortest, $8 \mathrm{~min}$; longest, $17 \mathrm{~min}$ ), and no respondents took more than $20 \mathrm{~min}$. In the results from which descriptive statistics were extracted, no items had a floor effect, and 35 items had a ceiling effect. Four items were identified as difficult to understand and six as difficult to answer. The likely reason for this is that the question items were inadequately expressed, making them difficult to answer. Consequently, the wording and terminology of 24 question items were revised so that patients could read them and feel a sense of realism with respect to dietary habit self-management. The terminology and syntax of the revised question items were examined by two nursing science specialists, who confirmed that the phraseology of the question items had become easier to understand. The revised scale was taken as the DHSMS scale (second draft).

\section{Study Methods}

\subsection{Participants}

The participants were post-gastrectomy cancer patients aged from 40 to under 80 years. The inclusion criteria of the participants were as follows: the patients had undergone first gastrectomy (regardless of the surgical technique), the patients were told of gastric cancer, the patients aged from 40 to under 80 years, 
and the patients were from one month following discharge to $<3$ years postoperative. The exclusion criteria of the participants were as follows: the patients with problems with cognitive function, the patients who were difficult to answer to the questionnaire, and the patients with severe digestive symptoms due to chemotherapy.

The sample size was calculated on the basis of the techniques used in scale development assuming an $80 \%$ response rate; the results indicated the need for a sample size of about 420 . Data on patients who had undergone gastrectomy were therefore collected on a nationwide scale from patient groups and three hospitals.

\subsection{Data Collection Method}

\subsubsection{Data Collection Period}

The data collection period was from November 2016 to July 2017.

\subsubsection{Data Collection Method}

Data were collected by an anonymous, self-administered questionnaire survey sent by post. Where the survey was carried out at a hospital, a researcher used the participant's time following an outpatient visit to explain the purpose and details of the survey both orally and in writing, and the questionnaire forms were handed to persons who consented to participate. The participants were asked to complete the questionnaire forms at home and then return them to the researcher by post. In the case of patient groups, the researcher sent an explanatory note about the survey and questionnaire forms to participants by post via the secretariat of the group, so that the researcher had no direct involvement with the personal data of the group members, and then the participants were requested to return the completed questionnaire by post. With regard to consent, returning of the questionnaire form by post was taken to mean that consent to participate had been given.

\subsection{Configuration of the Questionnaire Form}

The questionnaire form comprised the following: the Japanese version of the Medical Outcomes Study 8-item Short-Form Health Survey (SF-8) [17]; a health-related QOL scale that was included to examine criterion-related validity; the Self-Management Skill (SMS) scale [18], which was included to examine convergent validity; the DHSMS scale (second draft); and the attributes of subjects.

\subsubsection{The Japanese Version of the Medical Outcomes Study 8-Item Short-Form Health Survey}

The SF-8 [17] comprises a total of eight items, with one item measuring each of the eight concepts of physical functioning: PF (During the past 1 month, how much did physical health problems limit your physical activities such as walking or climbing stairs?), role physical: RP (During the past 1 month, how much difficulty did you have doing your daily work, both at home and away from home, 
because of your physical health?), bodily pain: BP (How much bodily pain have you had during the past 1 month?), general health perception: GH (Overall, how would you rate your health during the past 1 month?), vitality: VT (During the past 1 month, how much energy did you have?), social functioning: SF (During the past 1 month, how much did your physical health or emotional problems limit your usual social activities with family or friends?), role emotional: RE (During the past 1 month, how much did personal or emotional problems keep you from doing your usual work, school or other daily activities?), and mental health: MH (During the past 1 month, how much have you been bothered by emotional problems such as feeling anxious, depressed or irritable?). The reliability and validity of this tool have been confirmed. Post-gastrectomy disorder has been shown to affect QOL, and the acquisition of dietary habit self-management skills to prevent or cope with post-gastrectomy disorder is considered likely to improve QOL. A positive correlation was therefore predicted between the DHSMS scale (second draft) and the SF-8 Japanese version used in the present study.

\subsubsection{The Self-Management Skill Scale}

The SMS scale [19] is a scale of cognitive skills related to self-management that was developed for use with health education and other healthcare activities. The SMS scale comprises 10 items for the three factors "Skills in problem-solving procedures ("When trying to do something, I collect enough information", "When in trouble, I clarify what is the problem first.", etc.)", "Skills in control of negative thoughts ("Rather than doing what I have to do, I will make fun things first.", etc.)", and "Skills in delaying immediate gratification ("Rather than doing what I have to do, I will make fun things first.", etc.)". The reliability and validity of the scale have been confirmed. The cognitive skills related to self-management in the SMS scale were considered to be concepts with a high degree of relevance to the self-management skills of post-gastrectomy cancer patients in the present study, and a positive correlation was therefore predicted between the DHSMS scale (second draft) and the SMS scale.

\subsubsection{The Dietary Habit Self-Management Skills Scale (Second Draft)}

The DHSMS scale (second draft) would measure the details and the degree of problem-solving skills, resource utilization skills, formation of a patient-provider partnership skills, and self-efficacy, which are the skills necessary for addressing the three tasks of medical, role, and emotional management with regard to dietary habits in post-gastrectomy cancer patients.

The DHSMS scale (second draft) comprises 69 items. Items related to medical management are "I know how to prevent and treat symptoms that are likely to arise after gastric surgery such as dumping syndrome, gastric reflux, diarrheal constipation, weight loss, etc.", "I make judgments on or not I have developed dumping syndrome such as abdominal bloating, abdominal pain, nausea, abdominal discomfort, dullness, cold sweat, dizziness, finger tremor, headache, 
etc.", "I take time over a meaP", and so on. Items related to role management are

"I am aware that my roles at home, work, and community are likely to change due to changes in diet and body", "I make judgments on whether or not I need to adjust my roles at home", "I tell my family and those around me about things I want them to bear in mind about my meals and physical health", and so on. Items related to emotional management are "I am aware that changes in diet and body are likely to cause mental stress such as impatience, frustration, anxiety, fear, depression, etc.", "I make judgments on whether or not in changes in diet and body have caused mental stress", "I have my family and those near me listen to $m e$ ", and so on. Items related to self-efficacy is "I think I will be able to prevent and treat dumping syndrome in my own way", "I think I will be able to adjust my role within my family, my workplace, and the community in my own way for the sake of eating and health", and so on. Items related to utilization of resources were "I refer to the hospital meals and guidelines given to me", "I take into consideration the opinion of my family and people around me", and so on. Items related to a patient-provider partnership are "I consult with my medical care provider such as physician, nurse, nutritionist when I have problems", "I talk to my medical care provider about my physical wellness at visits ", and so on.

The content validity of the scale has been confirmed.

\subsubsection{Participants' Attributes}

The following attributes of the participants were compared: sex, age, occupation, operative procedure, postoperative period, family structure, and post-gastrectomy disorder symptoms. These have been shown to be related to dietary habit self-management skills in post-gastrectomy cancer patients in prior studies.

\subsection{Data Analysis Methods}

Statistical analysis using SPSS Statistics 23 and Amos 23 (IBM Corp.) was carried out to examine the reliability and validity of the DHSMS scale (second draft).

\subsubsection{Item Analysis}

The items were analyzed in terms of frequency distribution, reaction distribution, ceiling effect/floor effect, item-total (I-T) correlation, and item-item (I-I) correlation. Items with a ceiling or floor effect, and items with distortion in the responses found in the results for frequency distribution, reaction distribution, and I-T correlation are not valid as question items for the DHSMS scale. Therefore discarding such items was examined. In addition, an I-I correlation of 0.7 or greater indicates a high probability that the two correlated question items have the same semantic content; therefore, where this occurred, discarding one of the items was examined on the basis of the results for frequency distribution, reaction distribution, and I-T correlation. 


\subsubsection{Factor Analysis}

For the factor analysis, an exploratory factor analysis (EFA) using a principal factor method promax rotation and a confirmatory factor analysis (CFA) were performed.

The EFA was performed to confirm the factor structure and examine the construct validity of the DHSMS scale (second draft). The number of factors was determined with reference to the eigenvalues and the inflection point of the scree plot while confirming the validity of the interpretation of factors. For items with communality before rotation $<0.5$ and communality after rotation $<0.16$, the part that could be explained by the concept of dietary habit self-management skills in post-gastrectomy cancer patients was judged to be small, and these items were examined for discarding. In addition, for the items with a factor loading $<0.4$, the relationship with the concept of dietary habit self-management skills in post-gastrectomy cancer patients was judged to be weak, and these items were examined for discarding.

Next, a CFA of the factor model of the DHSMS scale detected by the EFA was performed using Amos 23 to check whether it fit the model of dietary habit self-management skills in post-gastrectomy cancer patients. The goodness of fit of the model was examined on the basis of goodness of fit index (GFI) $\geq 0.9$, adjusted GFI (AGFI) $\geq 0.9$, comparative fit index (CFI) $\geq 0.9$, and root mean square error of approximation (RMSEA) $<0.1[20]$.

\subsubsection{Analysis of Reliability}

For the analysis of reliability, Cronbach's alpha coefficient was calculated for each subscale extracted by factor analysis and for the overall scale to examine the internal consistency of the scale. In this analysis, the criterion for reliability was Cronbach's alpha coefficient $\geq 0.8$ [21]. In addition, the I-T correlation was calculated, and items with a correlation coefficient $<0.3$ were judged to lower the reliability of the scale; these items were then examined for discarding.

It is generally common to use the retest method when examining the reliability of a scale. However, the participants in the present study were post-gastrectomy cancer patients, whose post-gastrectomy disorders and dietary habit self-management skills change over time. Surveying the same patient twice was therefore judged likely to impair the rigor of the study, and for this reason, the retest method was not used.

\subsubsection{Analysis of Validity}

To investigate carefully the validity of the scale, it was examined from the point of view of: 1) content validity, 2) criterion-related validity, and 3) construct validity.

For content validity, the appropriateness of the process of drawing up the items was examined to determine whether the DHSMS scale covered all the details.

For criterion-related validity, the Pearson product-moment correlation coefficients of the DHSMS and SF-8 scales were calculated to examine relatedness. In 
addition, as the dietary habit self-management skills of post-gastrectomy cancer patients are acquired through experience, both the Pearson product-moment correlation coefficient of the DHSMS scale and the number of post-gastrectomy disorder symptoms experienced by patients were calculated to examine relatedness.

Construct validity was examined by EFA, CFA, and convergent validity. Convergent validity can be examined from the relationship with scales that are predicted to have a strong association with the concept. The Pearson product-moment correlation coefficients of the DHSMS and SMS scales were therefore calculated to examine relatedness.

\subsection{Ethical Considerations}

The present study was inspected and approved by the research ethics committee of the institution to which the researchers belong (approval no. 40-1969) and the ethics review committees of the facilities that were studied. A letter requesting participation in the study was included in the same envelope as the questionnaire forms for distribution to the participants; this letter stated clearly the objective of the study, that privacy and personal data protection would be strictly observed, as well as the methods that would be used for this, and that responding to and returning the questionnaire would be taken as consent to participate. The questionnaire forms were anonymous and the obtained data were anonymized before processing so that information could not be linked to individual participants.

\section{Results}

\subsection{Summary of the Study Participants}

Questionnaire forms were collected from 331 patients (response rate, 78.4\%). Of these, four who did not meet the selection criteria and five with values missing from the DHSMS (second draft) were excluded. Finally, the total number of participants included in the analysis was 322 .

The breakdown of participants included in the analysis is as follows: 211 responded as male (65.5\%), 109 responded as female (33.9\%), and 2 responded without indicating sex $(0.6 \%)$; mean age \pm standard deviation, $65.8 \pm 8.8$ years. In order of descending prevalence, the gastrectomy procedures performed were: 129 (40.1\%) total gastrectomy, 125 (38.8\%) distal gastrectomy, 30 (9.3\%) pylorus preserving gastrectomy, 24 (7.5\%) proximal gastrectomy, and $8(2.5 \%)$ segmental gastrectomy with 15 (4.5\%) as no response. A summary of the participants is shown in Table 1.

\subsection{Dietary Habit Self-Management Skills Scale (Second Draft) Descriptive Statistics}

Of the 69 items, those with the highest mean score were: "I have told my family 
Table 1. Demographic and health-related data $(n=322)$.

\begin{tabular}{|c|c|c|c|}
\hline \multicolumn{2}{|c|}{ Characteristic } & \multirow{2}{*}{$\begin{array}{c}\mathbf{N} \\
211\end{array}$} & \multirow{2}{*}{$\begin{array}{c}\% \\
65.5\end{array}$} \\
\hline Sex & Male & & \\
\hline & Female & 109 & 33.9 \\
\hline & No response & 2 & 0.6 \\
\hline \multirow[t]{5}{*}{ Age } & $40-49$ years & 20 & 6.2 \\
\hline & $50-59$ years & 51 & 15.8 \\
\hline & $60-69$ years & 132 & 41.0 \\
\hline & $70-79$ years & 117 & 36.3 \\
\hline & No response & 2 & 0.6 \\
\hline \multirow[t]{4}{*}{ Occupation } & Unemployed & 108 & 33.5 \\
\hline & Employed & 156 & 48.5 \\
\hline & Housewife & 56 & 17.4 \\
\hline & No response & 2 & 0.6 \\
\hline \multirow[t]{3}{*}{ Household } & Live alone & 35 & 10.9 \\
\hline & Live with family & 285 & 88.5 \\
\hline & No response & 2 & 0.6 \\
\hline \multirow[t]{4}{*}{ Cooker (multiple answers) } & Oneself & 147 & 45.7 \\
\hline & Members of a family & 192 & 59.7 \\
\hline & Do not cook at home & 14 & 4.3 \\
\hline & No response & 2 & 0.6 \\
\hline \multirow[t]{7}{*}{ Gastrectomy type } & Total gastrectomy & 129 & 40.1 \\
\hline & Distal gastrectomy & 125 & 38.8 \\
\hline & Pylorus preserving gastrectomy & 30 & 9.3 \\
\hline & Proximal gastrectomy & 24 & 7.5 \\
\hline & Segmental gastrectomy & 8 & 2.5 \\
\hline & Unknowns & 3 & 0.9 \\
\hline & No response & 3 & 0.9 \\
\hline \multirow[t]{7}{*}{ Time after surgery } & Under 5 months & 38 & 11.8 \\
\hline & $6-11$ months & 49 & 15.2 \\
\hline & $12-17$ months & 56 & 17.4 \\
\hline & $18-23$ months & 56 & 17.4 \\
\hline & $24-29$ months & 56 & 17.4 \\
\hline & $30-35$ months & 64 & 19.9 \\
\hline & No response & 3 & 0.9 \\
\hline \multirow[t]{3}{*}{$\begin{array}{c}\text { Experience of post-gastrectomy } \\
\text { disorder symptoms }\end{array}$} & Yes & 13 & 4.0 \\
\hline & No & 307 & 95.3 \\
\hline & No response & 2 & 0.6 \\
\hline
\end{tabular}




\section{Continued}

\begin{tabular}{cccc}
\hline $\begin{array}{c}\text { Post-gastrectomy disorder } \\
\text { symptoms (multiple answers) }\end{array}$ & Flatus & 235 & 76.5 \\
& Diarrhea & 228 & 74.3 \\
& Abdominal discomfort & 176 & 57.3 \\
& Difficulty in swallowing & 167 & 54.4 \\
& Abdominal bloating & 163 & 53.1 \\
Abdominal pain & 143 & 46.6 \\
Constipation & 142 & 46.3 \\
Nausea & 139 & 45.3 \\
Eructation & 137 & 44.6 \\
Cold sweat & 128 & 41.7 \\
Regurgitation & 127 & 41.4 \\
Fatigue & 126 & 41.0 \\
Heartburn & 113 & 36.8 \\
Trembling fingers & Palpitations & 31.6 & 17.6 \\
Headaches & 33 & 10.7 \\
\hline & Other & 11 & 3.6 \\
\hline
\end{tabular}

and people around me that I had stomach surgery" (score $=4.25$ ) and "I check my weight changes" (4.25), followed by "I check the situation of my bowel movements" (4.16) and "I know the symptoms that often occur as a result of stomach surgery (dumping symptoms, regurgitation, diarrhea/constipation, weight loss, etc.)" (4.12). The item with the lowest mean score was "I am taking nutritional supplements (supplements, nutrient preparations, energy drinks, Calorie Mate, etc.)" (2.43), followed by "I rest with my upper body raised" (2.47), and "I take nutritious foods in small quantities" (2.81).

Of the 69 items, seven with a ceiling effect and three with distortion in the responses found in the results for frequency distribution, reaction distribution, and I-T correlation were discarded. No items with a floor effect were found.

\subsection{Item-Item Correlation in the Dietary Habit Self-Management Skill Scale (Second Draft)}

I-I correlation of the remaining 59 items showed 11 pairs of items with a correlation coefficient of 0.7 or greater. These were examined from the point of view of the semantic content, the reaction distribution, and the frequency distribution of the question items by two nursing science specialists and one psychology specialist with expertise in scale development. As a result, 10 items that were each one of a pair with high correlation were discarded. 


\subsection{Factor Structure of the Dietary Habit Self-Management Skills Scale (Second Draft)}

\subsubsection{Exploratory Factor Analysis}

In the initial analysis, 49 remaining factors were identified after 20 were discarded in the item analysis, and factor extraction was performed using the principal factor method. The results showed that the eigenvalues, starting from the first factor, changed as follows: $15.11,3.15,2.78,2.15,1.54, \cdots$ The scree plot shows an inflection point between the third and fourth factors and between the fourth and fifth factor; therefore, analysis proceeded with hypotheses of three and four factors. In addition, 10 items with communality of less than 0.5 before rotation were discarded.

In the second analysis, the remaining 39 items after those with low communality were discarded and then analyzed by the principal factor method using promax rotation with three and four factors. No items with communality of $<0.16$ were found, and with an emphasis on the interpretation validity of the factors, the number of factors was taken as four. In addition, 10 items with factor loading $<0.4$ were discarded.

The third analysis was performed on the 29 items remaining after those with low factor loadings were discarded. The results showed one item that had two factors with a factor loading $\geq 0.4$ and one item that had a factor loading $<0.4$; these two items were discarded.

The fourth analysis was performed on the 27 items remaining after the item with two factors with a high factor loading and the item with a low factor loading were discarded. As a result, four factors and 27 items were extracted. The Kaiser-Meyer-Olkin sampling adequacy was 0.874 , and Bartlett's test of sphericity was significant $(p<0.001)$, thereby confirming the sampling adequacy. The final factor pattern and factor correlations are shown in Table 2.

The first factor comprised eight items related to building partnerships with other important people, such as medical professionals or family, and was therefore named "Skill to form partnerships with other important people". The second factor comprised seven items related to the behavior of post-gastrectomy cancer patients to prevent or cope with post-gastrectomy disorder, and was therefore named "Skill to prevent or cope with post-gastrectomy disorder". The third factor comprised eight items related to the skill of post-gastrectomy cancer patients to grasp their own issues with regard to dietary habits, and was therefore named "Skill to grasp issues accompanying post-gastrectomy disorder." The fourth factor comprised four items related to self-efficacy in self-management of post-gastrectomy cancer patients, and was therefore named "Self-efficacy."

\subsubsection{Confirmatory Factor Analysis}

CFA was performed with a model that assumed that the various factors influenced the corresponding items, and that there was covariance between all factors. The results for the goodness of fit indices were: $\chi^{2}(d f=318)=1137.250(p$ 
Table 2. Exploratory factor analysis of the dietary habit self-management skills scale.

\begin{tabular}{|c|c|c|c|c|c|}
\hline & \multirow{2}{*}{ Factor/item } & \multicolumn{4}{|c|}{ Factor loading } \\
\hline & & F1 & F2 & F3 & F4 \\
\hline \multicolumn{6}{|c|}{ Factor 1: Skill to form partnership with other important people } \\
\hline Q69 & $\begin{array}{l}\text { I tell my medical care provider (physician, nurse, nutritionist) } \\
\text { of my intensions, e.g., how I want to manage my condition }\end{array}$ & 0.811 & -0.120 & 0.032 & -0.015 \\
\hline Q67 & $\begin{array}{l}\text { I talk to my medical care provider (physician, nurse, nutritionist) } \\
\text { about my physical wellness at visits }\end{array}$ & 0.723 & -0.047 & 0.057 & -0.004 \\
\hline Q66 & I consult with my medical care provider (physician, nurse, nutritionist) when I have problems & 0.720 & -0.020 & -0.088 & 0.031 \\
\hline Q68 & I follow what my medical care provider (physician, nurse, nutritionist) tells me & 0.697 & 0.118 & 0.005 & -0.017 \\
\hline Q65 & I take into consideration the opinion of my family and people around me & 0.632 & 0.149 & -0.105 & 0.021 \\
\hline Q46 & I have my family and those near me listen to me & 0.571 & -0.005 & -0.002 & 0.085 \\
\hline Q49 & $\begin{array}{l}\text { I tell my family and those around me about things } \\
\text { I want them to bear in mind regarding my meals and physical health }\end{array}$ & 0.513 & 0.022 & 0.187 & -0.034 \\
\hline Q64 & I refer to the hospital meals and guidelines given to me & 0.489 & 0.161 & -0.067 & 0.132 \\
\hline \multicolumn{6}{|c|}{ Factor 2: Skill to prevent or cope with post-gastrectomy disorder } \\
\hline Q33 & I eat easily digestible foods & -0.026 & 0.803 & -0.020 & -0.010 \\
\hline Q35 & I try not to eat too much oily food & -0.025 & 0.747 & 0.002 & 0.012 \\
\hline Q36 & I avoid foods that are too cold, too hot, spicy, etc. & -0.020 & 0.678 & -0.023 & 0.038 \\
\hline Q30 & I take smaller bites & 0.110 & 0.665 & 0.014 & -0.068 \\
\hline Q26 & I take time over a meal & 0.082 & 0.617 & -0.045 & 0.086 \\
\hline Q29 & I eat until I feel about $80 \%$ full to avoid over-eating & 0.056 & 0.569 & 0.000 & 0.014 \\
\hline Q41 & I take nutritious foods in small quantities & -0.060 & 0.541 & 0.167 & -0.012 \\
\hline \multicolumn{6}{|c|}{ Factor 3: Skill to grasp issues accompanying post-gastrectomy disorder } \\
\hline Q7 & $\begin{array}{l}\text { I make judgments on whether or not I have developed dumping syndrome } \\
\text { (abdominal bloating, abdominal pain, nausea, abdominal discomfort, } \\
\text { dullness, cold sweat, dizziness, finger tremor, headache, etc.) }\end{array}$ & 0.170 & -0.043 & 0.747 & -0.156 \\
\hline Q3 & $\begin{array}{l}\text { I am aware that changes in diet and body are likely to cause mental stress } \\
\text { (impatience, frustration, anxiety, fear, depression, etc.) }\end{array}$ & -0.258 & 0.095 & 0.722 & 0.092 \\
\hline Q11 & $\begin{array}{l}\text { I make judgments on whether or not the changes in diet and body have caused mental stress } \\
\text { (impatience, frustration, anxiety, fear, depression, etc.) }\end{array}$ & -0.021 & 0.203 & 0.708 & -0.141 \\
\hline Q5 & $\begin{array}{l}\text { I am aware that my roles at home, work, and community are } \\
\text { likely to change due to changes in diet and body }\end{array}$ & -0.049 & -0.085 & 0.699 & 0.051 \\
\hline Q8 & I make judgments on whether or not I have developed gastric reflux or heartburn & 0.216 & 0.009 & 0.618 & -0.153 \\
\hline Q6 & I know how to adjust my roles at home, work, and community & 0.109 & -0.189 & 0.563 & 0.240 \\
\hline Q10 & I make judgments on whether or not I have taken sufficient nutrition for the day & -0.023 & 0.154 & 0.491 & 0.125 \\
\hline Q2 & $\begin{array}{l}\text { I know how to prevent and treat symptoms that are likely to arise after gastric surgery } \\
\text { (dumping syndrome, gastric reflux, diarrhea/constipation, weight loss, etc.) }\end{array}$ & -0.069 & -0.055 & 0.469 & 0.306 \\
\hline \multicolumn{6}{|c|}{ Factor 4: Self-efficacy } \\
\hline Q58 & I think I will be able to prevent and treat diarrhea and constipation in my own way & 0.000 & 0.020 & -0.048 & 0.824 \\
\hline Q59 & I think I will be able to consume the daily required nutrition in my own way & 0.043 & 0.048 & -0.060 & 0.740 \\
\hline Q56 & $\begin{array}{l}\text { I think I will be able to prevent and treat dumping syndrome } \\
\text { (abdominal bloating, abdominal pain, nausea, abdominal } \\
\text { discomfort, dullness, cold sweat, dizziness, finger tremor, headache, etc.) in my own way }\end{array}$ & -0.032 & 0.080 & 0.105 & 0.713 \\
\hline \multirow[t]{6}{*}{ Q61 } & $\begin{array}{l}\text { I think I will be able to adjust my role within my family, my workplace, } \\
\text { and the community in my own way for the sake of eating and health }\end{array}$ & 0.188 & -0.100 & 0.068 & 0.550 \\
\hline & Correlations among factors & $\mathrm{F} 1$ & F2 & F3 & $\mathrm{F} 4$ \\
\hline & $\mathrm{F} 1$ & - & 0.486 & 0.448 & 0.439 \\
\hline & $\mathrm{F} 2$ & & - & 0.417 & 0.347 \\
\hline & F3 & & & - & 0.469 \\
\hline & $\mathrm{F} 4$ & & & & - \\
\hline
\end{tabular}


$<0.001), \mathrm{GFI}=0.789, \mathrm{AGFI}=0.749, \mathrm{CFI}=0.800, \mathrm{RMSEA}=0.090$, and $\mathrm{AIC}=$ 1257.250. Correlations were found between each factor. CFA was therefore performed again with the hypothesis of a higher-order factor "Dietary habit self-management skills" between the four factors for which correlations were found. This time, the goodness of fit indices were $\chi^{2}(d f=320)=1142.515(p<$ $0.001), \mathrm{GFI}=0.788, \mathrm{AGFI}=0.750, \mathrm{CFI}=0.799, \mathrm{RMSEA}=0.089$, and $\mathrm{AIC}=$ 1258.515. The CFA results indicated goodness of fit within the tolerance limits; therefore, the four factors and 27 items were taken as the DHSMS scale. The results of the final second-order factor structural model of four factors and 27 items are shown in Figure 1.

\subsection{Examination of Reliability}

To examine internal consistency, Cronbach's alpha coefficient was calculated for the subscales of the DHSMS scale extracted by the EFA, and the I-T correlations were calculated for the overall scale (Table 3). Cronbach's alpha coefficient for the whole scale was 0.915 , and that for the scale with each item disregarded in turn was in the range of $0.910-0.913$. Thus, no items were found with a Cronbach's alpha coefficient higher than that of the whole scale. The I-T correlations were in the range of $0.444-0.610$. Furthermore, Cronbach's alpha coefficient for each subscale was in the range of $0.828-0.864$, and when calculated for the subscales with each item disregarded in turn, no item had a Cronbach's alpha coefficient greater than that of its overall subscale. The I-T correlations for each subscale were $\geq 0.3$.

\subsection{Examination of Validity}

Criterion-related validity was examined by calculating the correlation coefficients for the DHSMS scale and the SF-8 $(n=314)$, and the DHSMS scale and "number of post-gastrectomy disorder symptoms experienced" $(n=311)$, for respondents with no missing values in any of the responses. Convergent validity was examined by calculating the correlation coefficient for the DHSMS and SMS

Table 3. Summary of reliability of the dietary habit self-management skills scale.

\begin{tabular}{cccc}
\hline Scale & $\begin{array}{c}\text { Cronbach's alpha } \\
\text { coefficient }\end{array}$ & $\begin{array}{c}\text { Item-total } \\
\text { correlation }\end{array}$ & $\begin{array}{c}\text { Alpha if item } \\
\text { deleted }\end{array}$ \\
\hline DHSMS scale & 0.915 & $0.444-0.610$ & $0.910-0.913$ \\
$\begin{array}{c}\text { Skill to form partnership with } \\
\text { other important people }\end{array}$ & 0.864 & $0.558-0.674$ & $0.841-0.855$ \\
$\begin{array}{c}\text { Skill to prevent or cope with } \\
\text { post-gastrectomy disorder }\end{array}$ & 0.855 & $0.509-0.709$ & $0.823-0.851$ \\
$\begin{array}{c}\text { Skill to grasp issues accompanying } \\
\text { post-gastrectomy disorder }\end{array}$ & 0.856 & $0.513-0.662$ & $0.831-0.841$ \\
Self-efficacy & 0.828 & $0.565-0.722$ & $0.751-0.821$ \\
\hline
\end{tabular}


scales $(n=314)$.

\subsubsection{Participant Scores for Each Scale}

Scale scores calculated from the mean values for each item of the DHSMS scale are shown in Table 4. The overall DHSMS scale score was $3.30 \pm 0.65$, while the subscale with the highest score was "Skill to form partnerships with other important people" (3.40 \pm 0.84$)$, and that with the lowest score was "Self-efficacy" $(3.21 \pm 0.84)$.

The SF- 8 scores are shown in Table 5. With the exception of BP, all scores for the participants in the present study were lower than were the standard scores for Japanese people.

The SMS scale scores are shown in Table 6. The total SMS scale score was $29.89 \pm 4.02$, while the score for "Skills in problem-solving procedures" was $12.76 \pm 2.17$, for "Skills in control of negative thoughts" was $5.37 \pm 1.45$, and for "Skills delaying immediate gratification" was $5.67 \pm 1.35$.

\subsubsection{Relationship of the Dietary Habit Self-Management Skills Scale to Number of Post-Gastrectomy Disorder Symptoms Experienced, the Japanese Version of the Medical Outcomes Study 8-Item Short-Form Health Survey, and the Self-Management Skill Scale (Table 7)}

Weak positive correlations were found between the overall DHSMS scale score and "Number of post-gastrectomy disorder symptoms experienced" ( $r=0.204, p$ $<0.001$ ), and between "Skill to grasp issues accompanying post-gastrectomy disorder" and "Number of post-gastrectomy disorder symptoms experienced" ( $r$ $=0.306, p<0.001$ ).

No correlations were found between the overall DHSMS scale score and SF-8 subscale scores. Weak positive correlations were found between the "Self-efficacy" score and PCS $(r=0.291, p<0.001)$, and between the "Self-efficacy" score and MCS $(r=0.258, p<0.001)$.

Weak to moderate positive correlations were found between the overall DHSMS scale score and the overall SMS scale score $(r=0.377, p<0.001)$, and between the overall DHSMS scale score and "Skills in problem-solving procedures" ( $r=0.412, p<0.001$ ). However, no correlation was found between the overall DHSMS scale score and "Skills in controlling negative thoughts" ( $r=$ 0.087 , not significant). And, almost no correlation was found between the overall DHSMS scale score and "Skills in delaying immediate gratification" $(r=0.194, p$ $<0.01)$.

\section{Discussion}

\subsection{Participants' Backgrounds}

Among Japanese gastric cancer patients aged from 40 to under 80 years in 2014, the proportion of men and women was $74.0 \%$ and $26.0 \%$, respectively [22]. The percentage of females was somewhat higher among the participants of the present study, but the proportions were fairly close to those of the nationwide 


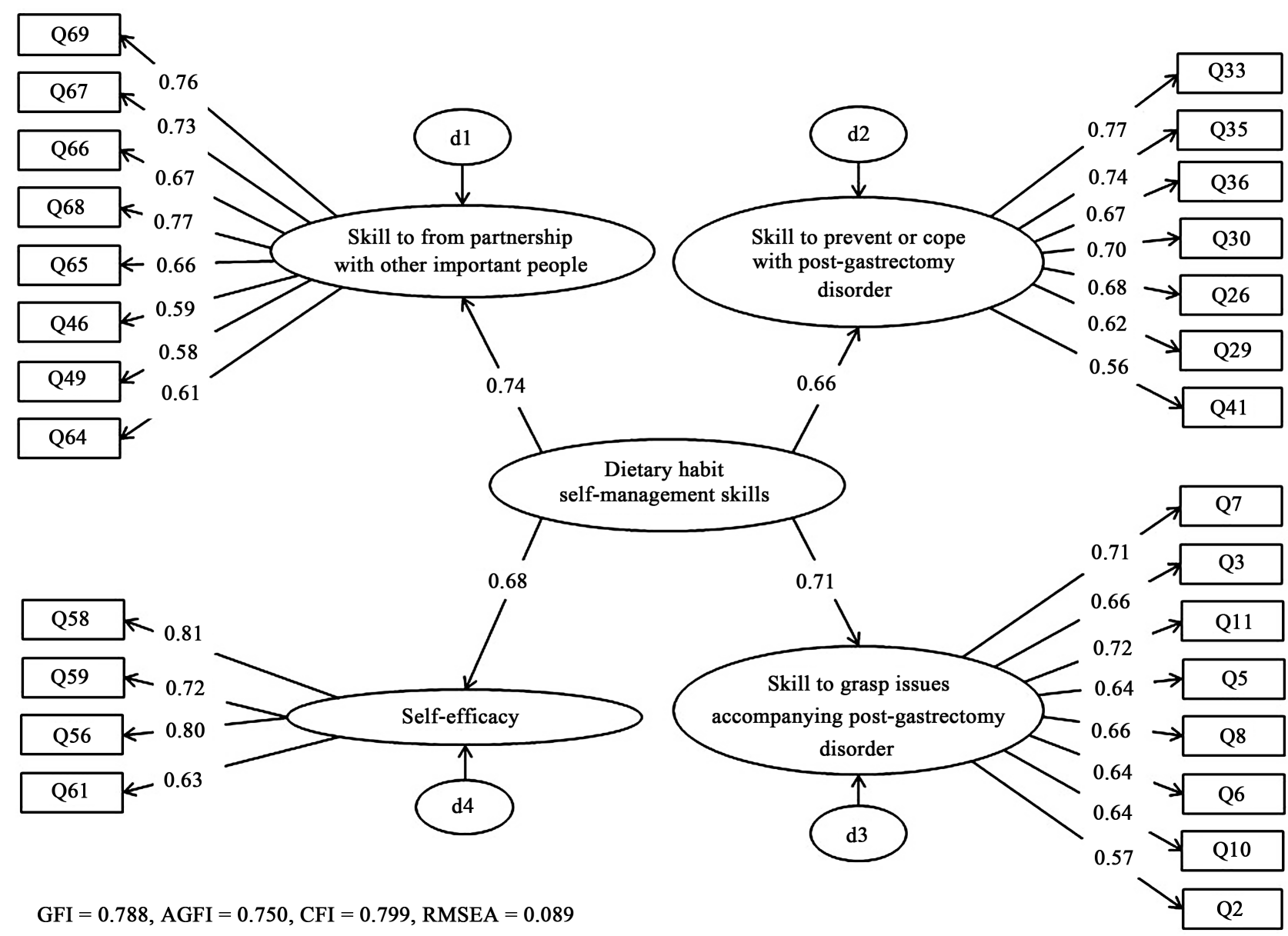

Figure 1. Confirmatory factor analysis of the dietary habit self-management skills scale.

Table 4. The dietary habit self-management skills scale score $(n=314)$.

\begin{tabular}{cccc}
\hline & Mean \pm SD & Min & Max \\
\hline Skill to form partnership with other important people & $3.40 \pm 0.84$ & 0.88 & 5.00 \\
Skill to prevent or cope with post-gastrectomy disorder & $3.24 \pm 0.87$ & 0.29 & 5.00 \\
Skill to grasp issues accompanying post-gastrectomy disorder & $3.29 \pm 0.84$ & 0.13 & 5.00 \\
Self-efficacy & $3.21 \pm 0.84$ & 0.00 & 5.00 \\
Total score & $3.30 \pm 0.65$ & 1.11 & 4.85 \\
\hline
\end{tabular}

SD: standard deviation.

survey. In addition, the distribution of Japanese gastric cancer patients aged from 40 to under 80 years in 2014 was: 40 s, $4.0 \%$; 50 s, 11.4\%; 60 s, 37.1\%; and $70 \mathrm{~s}, 47.4 \%$ [22]. Among the participants in the present study, there were slightly more people in their $60 \mathrm{~s}$ and slightly fewer in their 70s compared with the nationwide survey, but the age distribution of the present participants was similar. From these results, it can be judged that the participants in the present study were a valid population for the development of a DHSMS scale targeting Japanese post-gastrectomy cancer patients. 
Table 5. The Japanese version of the medical outcomes study 8 -item short-form health survey score $(\mathrm{n}=314)$.

\begin{tabular}{cccc}
\hline & & Mean \pm SD & National standard values \\
\hline PF & Physical functioning & $47.17 \pm 8.21$ & 50.85 \\
RP & Role physical & $45.97 \pm 8.26$ & 50.65 \\
BP & Bodily pain & $52.55 \pm 7.81$ & 51.42 \\
GH & General health perception & $48.62 \pm 7.08$ & 50.99 \\
VT & Vitality & $49.96 \pm 6.73$ & 51.76 \\
SF & Social functioning & $45.82 \pm 8.97$ & 50.09 \\
RE & Role emotional & $47.05 \pm 7.72$ & 50.89 \\
MH & Mental health & $48.82 \pm 7.01$ & 50.96 \\
PCS & Physical component summary & $47.51 \pm 7.45$ & 49.84 \\
MCS & Mental component summary & $47.08 \pm 7.03$ & 50.09 \\
\hline
\end{tabular}

SD: standard deviation.

Table 6. The self-management skill scale score $(\mathrm{n}=314)$.

\begin{tabular}{cc}
\hline & Mean \pm SD \\
\hline Skills in problem-solving procedures & $12.76 \pm 2.17$ \\
Skills in control of negative thoughts & $5.37 \pm 1.45$ \\
Skills in delaying immediate gratification & $5.67 \pm 1.35$ \\
Total score & $29.89 \pm 4.02$ \\
\hline
\end{tabular}

SD: standard deviation.

\subsection{Dietary Habit Self-Management Skills Scale Factor Structure}

As a result of the EFA and CFA, a second-order factor model comprising four factors, with "Dietary habit self-management skills" as a higher-order factor, and 27 items was extracted. Although this model was rejected by the $\chi^{2}$ goodness of fit test, the sample size in the present study was medium to large $(n=322)$; therefore, the goodness of fit may be interpreted as an index [23]. With the second-order factor model of the DHSMS scale, GFI (0.788), AGFI (0.750), and CFI (0.799) were all somewhat lower than 0.9, even though GFI was greater than or equal to AGFI. Where the number of items is large, as in the present study, the degrees of freedom become greater, and thus it is probably not necessary to discard a model, even when GFI is below 0.9 [24]. The RMSEA of 0.089 was less than or equal to 0.1 , and fitting to the model may be judged as valid. The DHSMS scale therefore has a second-order factor model and simple calculation of overall score and scores for the individual subscales.

\subsection{Reliability of the Dietary Habit Self-Management Skills Scale}

Cronbach's alpha coefficient for the overall DHSMS scale was 0.915, and that for the individual subscales was in the range of $0.828-0.864$. A scale with a Cron- 
Table 7. Relationship of the dietary habit self-management skills scale to number of post-gastrectomy disorder symptoms experienced, the Japanese version of the Medical Outcomes Study 8-item Short-Form Health Survey score, and the self-management skill scale.

(a)

\begin{tabular}{cc}
\hline & Number of post-gastrectomy disorder symptoms experienced \\
\hline Skill to form partnership with other important people & $0.114^{*}$ \\
Skill to prevent or cope with post-gastrectomy disorder & $0.119^{*}$ \\
Skill to grasp issues accompanying post-gastrectomy disorder & $0.306^{* * *}$ \\
Self-efficacy & 0.000 \\
Total score & $0.204^{* * *}$ \\
\hline
\end{tabular}

(b)

\begin{tabular}{|c|c|c|c|c|c|c|c|c|c|c|}
\hline & \multicolumn{10}{|c|}{$\begin{array}{l}\text { The Japanese version of the Medical Outcomes } \\
\text { Study 8-item Short-Form Health Survey }\end{array}$} \\
\hline & PF & RP & BP & GH & VT & SF & $\mathrm{RE}$ & $\mathrm{MH}$ & PCS & MCS \\
\hline $\begin{array}{c}\text { Skill to form } \\
\text { partnership } \\
\text { with other } \\
\text { important people }\end{array}$ & 0.020 & 0.025 & 0.013 & 0.080 & 0.079 & 0.010 & 0.037 & 0.038 & 0.030 & 0.042 \\
\hline $\begin{array}{l}\text { Skill to prevent or } \\
\text { cope with } \\
\text { post-gastrectomy } \\
\text { disorder }\end{array}$ & -0.078 & -0.109 & -0.083 & -0.025 & -0.085 & $-0.156^{* *}$ & $-0.146^{* *}$ & -0.111 & -0.065 & $-0.146^{* *}$ \\
\hline $\begin{array}{c}\text { Skill to grasp issues } \\
\text { accompanying } \\
\text { post-gastrectomy } \\
\text { disorder }\end{array}$ & 0.020 & 0.001 & -0.042 & 0.001 & -0.016 & -0.089 & -0.057 & $-0.112^{*}$ & 0.036 & $-0.122^{* *}$ \\
\hline Self-efficacy & $0.280^{* * *}$ & $0.298^{* * *}$ & $0.205^{* * *}$ & $0.328^{* * *}$ & $0.304^{* * *}$ & $0.230^{* * *}$ & $0.315^{* * *}$ & $0.257^{* * *}$ & $0.291^{* * *}$ & $0.258^{* * *}$ \\
\hline Total score & 0.042 & 0.030 & -0.001 & 0.086 & 0.086 & -0.041 & 0.002 & -0.018 & 0.059 & -0.032 \\
\hline
\end{tabular}

PF: Physical functioning, RP: Role physical, BP: Bodily pain, GH: General health perception, VT: Vitality, SF: Social functioning, RE: Role emotional, MH: Mental health, PCS: Physical component summary, MCS: Mental component summary.

(c)

\begin{tabular}{ccccc}
\hline & \multicolumn{3}{c}{ The Self-Management Skill scale } \\
\cline { 2 - 5 } & $\begin{array}{c}\text { Skills in } \\
\text { problem-solving } \\
\text { procedures }\end{array}$ & $\begin{array}{c}\text { Skills in } \\
\text { control of } \\
\text { negative } \\
\text { thoughts }\end{array}$ & $\begin{array}{c}\text { Skills in } \\
\text { delaying } \\
\text { immediate } \\
\text { gratification }\end{array}$ & $\begin{array}{c}\text { Total } \\
\text { score }\end{array}$ \\
\hline Skill to form partnership with other important people & $0.345^{* * *}$ & 0.059 & $0.150^{* *}$ & $0.302^{* * *}$ \\
Skill to prevent or cope with post-gastrectomy disorder & $0.251^{* * *}$ & 0.038 & $0.256^{* * *}$ & $0.274^{* * *}$ \\
Skill to grasp issues accompanying post-gastrectomy disorder & $0.347^{* * *}$ & 0.042 & 0.373 & 0.000 \\
Self-efficacy & $0.302^{* * *}$ & $0.184^{* *}$ & $0.143^{* *}$ & $0.343^{* * *}$ \\
Total score & $0.412^{* * *}$ & 0.087 & $0.194^{* *}$ & $0.377^{* * *}$ \\
\hline
\end{tabular}

Pearson product-moment correlation coefficients: ${ }^{* * *} p<0.001,{ }^{* *} p<0.01,{ }^{*} p<0.05$. 
bach's alpha coefficient of 0.8 or higher is generally judged to have high reliability [21]; therefore, the internal consistency of the DHSMS scale was confirmed. In addition, when Cronbach's alpha coefficient was calculated for the DHSMS with each item disregarded in turn, no items were found for which Cronbach's alpha coefficient exceeded that of the scale overall, thereby confirming the high reliability of the scale. Moreover, calculation of the I-T correlations showed that none of the items had a correlation $<0.3$, indicating that the DHSMS scale maintained satisfactory internal consistency.

\subsection{Validity of the Dietary Habit Self-Management Skills Scale}

\subsubsection{Content Validity}

When the DHSMS scale items were drawn up, content related to the dietary habit self-management of post-gastrectomy cancer patients was selected from the point of view of both post-gastrectomy cancer patients and medical professionals such as nurses and doctors, and a matrix table was used to check that the items were exhaustive. Furthermore, content validity was examined by seven nursing science specialists and one nutritionist involved with post-gastrectomy cancer patients. In addition, a pretest was carried out, and the question items were examined and verified by specialists. An item analysis of the validity of the question items was also carried out to examine the relationships between the items and the reaction distribution, and the DHSMS scale was configured so that question items had varied reactions.

From the above results, the DHSMS scale is considered to cover the Dietary habit self-management skills of post-gastrectomy cancer patients exhaustively. It is composed of appropriate question items that can assess individual differences among patients, and its content validity was maintained.

\subsubsection{Criterion-Related Validity}

In the present study, self-management skills are taken as something acquired by post-gastrectomy cancer patients through experience. It was therefore predicted that the more a patient experienced post-gastrectomy disorder symptoms, the higher the DHSMS scale score would be. The correlation between the DHSMS scale and "Number of post-gastrectomy disorder symptoms experienced" was analyzed, and the correlations observed between overall DHSMS scale scores and "Number of post-gastrectomy disorder symptoms experienced", and between "Skill to grasp issues accompanying post-gastrectomy disorder" and "Number of post-gastrectomy disorder symptoms experienced", confirmed the criterion-related validity.

Health-related QOL is defined as comprising the three basic elements of physical function, mental health, and social activity/role function [25]. It was therefore predicted that if the DHSMS score were high, the SF-8 score would also be high. The correlation between the DHSMS scale and the SF- 8 was analyzed, and the results regarding the correlation between "Self-efficacy" and all SF-8 subscale scores and the SF-8 summary score confirmed the criterion-re- 
lated validity. However, it was not possible to confirm criterion-related validity from overall DHSMS scores and the SF-8. The likely reason for this is as follows. A study of post-gastrectomy patients up to 3 years postoperative showed that there is low possibility of clear improvement in post-gastrectomy disorder symptoms over time [3]. It has also been shown that even after discharge from hospital, post-gastrectomy patients continue to have reduced QOL because of the appearance of physical symptoms of post-gastrectomy disorder, and even if the physical factors improve, there remains a delay in improvement of the psychological factors over time [7]. There is also a report that a depressive state persists in gastrointestinal cancer patients, even after discharge from hospital [26]. Based on these findings, patients less than 3 years post-gastrectomy are in a situation where it is hard for their QOL to improve. It therefore appears that there was no correlation between overall DHSMS scores and the SF-8 in the present study because the participants were cancer patients less than 3 years post-gastrectomy, and the study was a cross-sectional study conducted at only one time point.

\subsubsection{Construct Validity}

When the component elements of the measurement concept on which the DHSMS scale was premised were compared to the extracted component factors of the DHSMS scale, "Skill to grasp issues accompanying post-gastrectomy disorder" consisted of "problem recognition" and "problem analysis and judgment" from among the elements making up problem-solving skills. In addition, "Skill to prevent or cope with post-gastrectomy disorder" consisted of "implementing solution strategies" from among the elements making up problem-solving skills. Question items related to the problem-solving elements of "establishment of goals for problem-solving" and "planning solution strategies" showed high I-I correlation and low communality; these items were therefore discarded after an examination by a specialist. From these results, it was conjectured that the establishment of goals and planning solution strategies are not consciously carried out by post-gastrectomy cancer patients. This means that post-gastrectomy cancer patients need "Skill to grasp issues accompanying post-gastrectomy disorder" and "Skill to prevent or cope with post-gastrectomy disorder" to understand the issues in regard to dietary habits. "Skill to form partnerships with other important people" comprised resource utilization skills and the skills needed for forming partnerships with medical professionals. In addition, the problem-solving elements, "I have my family and those near me listen to me" and "I tell my family and those around me about things I want them to bear in mind regarding my meals and physical health", which represent the implementation of problem-solving strategies, were included. Self-management is a dynamic process in which patients cooperate with their families and medical care providers to monitor and manage their own chronic health condition [27], and the inclusion of these elements in "Skill to form partnerships with other important people" appears to be valid. "Self-efficacy" comprises the self-efficacy elements 
that were taken as a premise, and showed agreement with the items that were extracted at the stage of drawing up the DHSMS items.

The factor structure of four factors and 27 items that was extracted by EFA was examined using CFA, and a goodness of fit within the acceptable limits was obtained for the second-order factor model of the DHSMS scale with "Dietary habit self-management skills" as a higher order factor.

The self-management skills of the SMS scale are cognitive skills with a high degree of generality that can be applied to a variety of behavioral settings [18]. It was therefore predicted that if the DHSMS scale score were high, the SMS scale score would also be high. Analysis of the correlation between overall DHSMS scale scores and overall SMS scale scores showed a weak positive correlation. In addition, a weak positive correlation was observed between all individual subscale scores of the DHSMS scale and the score for "Skills in problem-solving procedures" on the SMS scale, and a positive correlation was observed between overall DHSMS scale scores and the score for "Skills in problem-solving procedures" on the SMS scale. The DHSMS scale measures self-management skills specific to the situation of the dietary habits of post-gastrectomy cancer patients. This is probably the reason why, although a positive correlation was found with the SMS scale, which measures highly generalized cognitive skills, the relationship was weak.

The above results confirm the construct validity of the DHSMS scale, but it was not possible to adequately confirm the convergent validity of the DHSMS or SMS scale.

\subsection{Implications for Nursing Practice}

The question items of the DHSMS scale developed in the present study represent the Dietary habit self-management skills of post-gastrectomy cancer patients. In addition, the scores for the question items indicate the degree of acquisition of these self-management skills, such that a lower score on a given item means that the respondent needs support for his or her self-management with respect to that particular item. The overall DHSMS scale scores represent the overall trend in the Dietary habit self-management skills of post-gastrectomy cancer patients. By using patients' self-administered DHSMS scale scores, medical professionals are able to assess the level of a patient's self-management skills and the status of their dietary habits as a result of post-gastrectomy disorder. Based on the results of this assessment, it is possible to plan support that is tailored to individual patients according to the status of their self-management skills acquisition. Furthermore, using the DHSMS scale over time allows it to serve as an index for the evaluation of self-management support interventions. Moreover, the DHSMS scale can be used by post-gastrectomy cancer patients as an index for self-evaluation, as it allows patients to see the level of Dietary habit self-management skills that they have acquired and highlights issues that they need to address in the future. 


\subsection{Issues in the Present Study}

The criterion-related validity of both the DHSMS scale and the SF-8 were only partially confirmed, and thus, the relationship between the two scales in terms of changes over time in the DHSMS scale scores and the SF-8 needs to be verified. Furthermore, in the examination of convergent validity, a weak correlation was observed between the DHSMS and SMS scales. Therefore, further validation, which should include the use of other scales, is needed.

\section{Conclusions}

1) The scale is a second-order factor model with "Dietary habit self-management skills" as a higher-order factor, four factors-"Skill to form partnerships with other important people", "Skill to prevent or cope with post-gastrectomy disorder", "Skill to grasp issues accompanying post-gastrectomy disorder", and "Self-efficacy" - and 27 items. The construct validity of the scale was confirmed.

2) The internal consistency of the DHSMS scale and its various subscales was confirmed.

3) The criterion-related validity of the DHSMS scale was confirmed based on the correlations between overall DHSMS scale scores and "Number of post-gastrectomy disorder symptoms experienced", the score for the subscale "Skill to grasp issues accompanying post-gastrectomy disorder" and "Number of postgastrectomy disorder symptoms experienced", and the subscale "Self-efficacy" and the SF-8.

\section{Acknowledgements}

The author would like to express her deepest gratitude to the patients who willingly took part in this study, and to the staff of the medical institutions involved in this study. I would also like to thank Mr. Yoichi Yamano, a part-time lecturer at Osaka University of Human Sciences, for supervising the data analysis. I would also like to express sincere gratitude to Prof. Kumi Suzuki, Prof. Tomotaro Dote, and Associate Prof. Emiko Kusano of Osaka Medical College Faculty of Nursing for their advice on the thesis.

This study was research for the doctoral course of Osaka Medical College Faculty of Nursing Graduate School, and was funded in part by a Grant-in Aid for Scientific Research for Young Scientists (B) (Project No. 15K20700). Part of this thesis was presented at the 3rd Asian Oncology Nursing Society Conference (September 23, 2017, Beijing, China).

\section{Conflict of Interest}

The authors declare no conflict of interest.

\section{References}

[1] Matsuda, A., Matsuda, T., Shibata, A., Katanoda, K., Sobue, T., Nishimoto, H. and The Japan Cancer Surveillance Research Group (2013) Cancer Incidence and Inci- 
dence Rates in Japan in 2008: A Study of 25 Population-Based Cancer Registries for the Monitoring of Cancer Incidence in Japan (MCIJ) Project. Japanese Journal of Clinical Oncology, 44, 388-396. https://doi.org/10.1093/jjco/hyu003

[2] Iino, K., Watanuki, S., Koyama, Y., Suzuki, K., Wada, C., Mori, M., et al. (2013) Signs and Symptoms Associated with Postsurgical Dysfunctions among Upper Gastroesophageal Cancer Patients: An Analysis of the Published Reports. Palliative Care Research, 8, 701-720. https://doi.org/10.2512/jspm.8.701

[3] Nakamura, M., Hosoda, Y., Doki, Y., Yano, M. and Alan, T.L. (2014) Development of the DAUGS Scoring System. Kyoto University Press, Kyoto.

[4] Ministry of Health, Labor and Welfare (2012) 2011 Summary of Patient Survey, Average Length of Preoperative and Postoperative Stay for Estimated Discharged Patients. http://www.mhlw.go.jp/toukei/saikin/hw/kanja/11/dl/03.pdf

[5] Nawa, H., Shimazawa, J., Takeda, K., Yasuda, K., Mikoshiba, Y., Miyauchi, K., et al. (2005) Symptom Management and Features of Postgastrectomy Patient's Daily Life during Transitional Stage. Bulletin Nagano College of Nursing, 7, 11-20. http://id.nii.ac.jp/1054/00000009/

[6] Yamawaki, K. and Fujita, M. (2004) Stress Associated with Resumption of Work in Middle-Aged People after Surgery for Gastric Cancer. Research reports of the Kôchi University, 53, 47-63. http://hdl.handle.net/10126/135

[7] Takashima, N. and Murata, Y. (2013) Quantitative and Qualitative Evaluation of the Quality of Life of Patients with Gastric Cancer up to 2 Months after Gastrectomy. Tokyo Jikeikai Medical Journal, 128, 25-34. http://hdl.handle.net/10328/7747

[8] Yoshimura, Y., Maeda, Y. and Shirata, K. (2005) Quality of Life in Cancer Patients after Gastrectomy by Evaluating Correlation between Eating Habits and Postoperative Symptoms, and Psychological Health. Journal of Japan Academy of Nursing Science, 25, 52-60. https://doi.org/10.5630/jans1981.25.4_52

[9] Enomoto, M., Saegusa, K., Nakai, Y. and Sato, H. (2007) A Review of the Dietary Behavior in Patients after Gastrectomy for Gastric Cancer. Bulletin of Chiba College of Health Science, 26, 123-129. http://id.nii.ac.jp/1141/00275450/

[10] Nakada, K., Ikeda, M., Takahashi, M., Kinami, S., Yoshida, M., Uenosono, Y., et al. (2015) Characteristics and Clinical Relevance of Postgastrectomy Syndrome Assessment Scale (PGSAS)-45: Newly Developed Integrated Questionnaires for Assessment of Living Status and Quality of Life in Postgastrectomy Patients. Gastric Cancer, 18, 147-158. https://doi.org/10.1007/s10120-014-0344-4

[11] Copland, L., Liedman, B., Rothenberg, E. and Bosaeus, I. (2007) Effects of Nutritional Support Long Time after Total Gastrectomy. Clinical Nutrition, 26, 605-613. https://doi.org/10.1016/j.clnu.2007.06.004

[12] Faller, H., Koch, G.F., Reusch, A., Pauli, P. and Allgayer, H. (2009) Effectiveness of Education for Gastric Cancer Patients: A Controlled Prospective Trial Comparing Interactive vs. Lecture-Based Programs. Patient Education \& Counseling, 76, 91-98. https://doi.org/10.1016/j.pec.2008.11.021

[13] Xie, F.L., Wang, Y.Q., Peng, L.F., Lin, F.Y., He, Y.L. and Jiang, Z.Q. (2017) Beneficial Effect of Educational and Nutritional Intervention on the Nutritional Status and Compliance of Gastric Cancer Patients Undergoing Chemotherapy: A Randomized Trial. Nutrition \& Cancer, 69, 762-771. https://doi.org/10.1080/01635581.2017.1321131

[14] Lorig, K.R. and Holman, H.R. (2003) Self-Management Education: History, Definition, Outcomes, and Mechanisms. Annals of Behavioral Medicine, 26, 1-7. https://doi.org/10.1207/S15324796ABM2601_01 
[15] Japanese Society for Gastro-Surgical Pathophysiology (2015) Practical Handbook for Gastro-Surgical Pathophysiology. Nankodo Ltd., Tokyo.

[16] Wakita, T. (2007) Drawing up the Scale Items. In: Oshio, S. and Nishiguchi, T., Eds., Process for Questionnaire Survey, Nakanishiya Ltd., Kyoto, 49-53.

[17] Fukuhara, S. and Suzukamo, Y. (2004) Manual of the SF-8 Japanese Version. Institute for Health Outcomes \& Process Evaluation Research, Kyoto.

[18] Takahashi, H., Nakamura, M., Kinoshita, T. and Masui, S. (2000) Development and Validation of a Self-Management Skill Scale. Japanese Journal of Public Health, 47, 907-914.

[19] Takahashi, H., Takehana, Y. and Sami, Y. (2004) Difference of Self-Management Skills among Various Age Groups. Japanese Journal of Health Education and Promotion, 12, 80-87.

[20] Oshio, S. (2010) Covariance Structure Analysis First Step, Introduction to Path Analysis Learned from the Meaning of Figure. Arute Ltd., Tokyo.

[21] Polit, D.F. and Beck, C.T. (2004) Nursing Research: Principles and Methods. 7th Edition, Lippincott Williams \& Wilkins, Philadelphia.

[22] Ministry of Health, Labor and Welfare (2015) 2014 Patient Survey, Estimated Number of Discharged Patients by Sex, Age Group and Classification of Diseases. https://www.e-stat.go.jp/SG1/estat/GL08020103.do?_toGL08020103_\&listID=00000 1141596\&requestSender $=$ dsearch

[23] Kojima, T. (2008) Trouble Shooting. In: Asano, H., Suzuki, T. and Kojima, T., Eds., Actual of Covariance Structure Analysis, Kodansha Ltd., Tokyo, 118-122.

[24] Toyota, H. (1998) Covariance Structure Analysis [Introduction]: Structural Equation Modeling. Asakura Publishing Ltd., Tokyo, 173-177.

[25] Takegami, M. and Fukuhara, S. (2009) How to Use QOL That No One TaughtConnect Measurement Results to Research, Medical Treatment, and Policy: SF-36 Utilization Version. 2nd Edition, Institute for Health Outcomes \& Process Evaluation Research, Kyoto.

[26] Matsushita, T., Matsushima, E. and Maruyama, M. (2005) Psychological Characteristics of Patients with Digestive Cancer. Japanese Journal of General Hospital Psychiatry, 17, 37-47.

[27] Knobf, M.T. (2015) Oncology Nursing Society 2014-2018 Research Agenda. https://www.ons.org/sites/default/files/2014-2018\%20ONS\%20Research\%20Agenda pdf 